\title{
Cryptogenic fibrosing alveolitis: prediction of fibrogenic activity from immunohistochemical studies of collagen types in lung biopsy specimens
}

\author{
ED BATEMAN, M TURNER-WARWICK, PL HASLAM, BC ADELMANN-GRILL \\ From the Department of Medicine, Cardiothoracic Institute, Brompton Hospital, London, and \\ Max-Planck-Institut für Biochemie, Munich, West Germany
}

ABSTRACT Collagen immunofluorescence studies were performed on biopsy specimens from 25 patients with cryptogenic fibrosing alveolitis. We studied the relationship of these results to the clinical, radiological, and physiological assessments of disease activity during six-month periods before and after the lung biopsy; to the appearances on routine histological examination; to the inflammatory cell proportions in bronchoalveolar lavage fluid; and to the response to treatment. Positive associations were observed between the presence of type III collagen and disease activity before $(p<0.015)$ and after $(p<0.02)$ lung biopsy. These were independent of clinical and routine histological features. The type-III-positive group also contained nine of the 11 responding to treatment. None of the type-III-positive patients had a quiescent or stable course. In contrast, most patients with no type-III-collagen fluorescence had a stable course over the time of this study and did not improve on treatment. It is suggested that collagen typing may be an additional useful method of assessing potentially reversible disease in cryptogenic fibrosing alveolitis.

Patients fulfilling the clinical criteria for cryptogenic fibrosing alveolitis ${ }^{1}$ form a heterogeneous group in respect of histological features, response to treatment, and rate of progression of disease. The variable survival rate was well illustrated in a recent large, retrospective study. ${ }^{2}$ Half of the patients had died within 3.2 years of first hospital attendance, but a quarter were still alive after 10 years. Furthermore, the mean survival of untreated patients was longer than that of patients who were treated but failed to respond. ${ }^{3}$

In view of this variability, the assessment of activity and potential reversibility of disease becomes important if patients are to be treated at an appropriate time and before irreversible fibrosis has occurred. Clinical, physiological, and radiological data; ${ }^{2-8}$ grading of histological features; ${ }^{256}$ inflammatory cell proportions in bronchoalveolar lavage fluid $7^{7-11}$ and gallium-67-citrate lung scans ${ }^{8}$ have all been used for this purpose. Combinations of these are useful for determining disease severity,

Address for reprint requests: Dr ED Bateman, Department of Medicine, University of Cape Town Medical School, Observatory 7925, South Africa. and to a lesser extent for confirming disease activity. Their value in predicting response to treatment has, however, been poor.

Several, but not all, studies have emphasised that corticosteroid responsiveness tends to relate to more cellular and less fibrotic change in lung biopsies, ${ }^{3-6} 12$ but there are many exceptions and in particular not all patients with cellular disease respond. For example, $10(38.5 \%)$ of 26 cases classified as desquamative interstitial pneumonitis failed to improve on corticosteroids. ${ }^{4}$ The need for more reliable methods remains.

Several idiotypes of the collagen molecule are found in the lung, each with its distinctive fibril form, functional characteristics, and biological properties. Type I collagen is the most plentiful collagen in normal organs and in scar tissue. During the early phases of fibrosis and scar formation in the lung, however, as in other tissues, the ratio of type III to type I collagen increases temporarily. ${ }^{13-15} \mathrm{On}$ the basis of collagen immunofluorescence studies we have suggested that areas of mature collagen in sites of established (and probably irreversible) scar tissue in lung can be distinguished from areas of early active fibrosis, and that this information might be 
useful in the management of certain lung disorders. ${ }^{13}$ We report here a study of lung biopsy specimens from patients with cryptogenic fibrosing alveolitis and describe the relationship between results of collagen immunofluorescence studies and appearances on routine histological examination; clinical, radiological, and physiological data; inflammatory cell proportions from bronchoalveolar lavage fluid; and response to treatment. The value of these results in determining disease activity and hence identifying the patients who require treatment has been established.

\section{Methods}

Lung biopsy specimens with histological features in keeping with cryptogenic fibrosing alveolitis were obtained from 25 patients with clinical, physiological, and radiological evidence of the condition. ${ }^{1}$ Widespread and persistent crepitations were present in 22 patients, breathlessness in 23 , and finger clubbing in 18.

The group (table 1) included 18 men and 7 women and their mean age was 54.2 ( $\pm 8 \mathrm{SD})$. In 14 the lung alone was affected, the remainder having associated disorders of other systems. Three hä rheumatoid arthritis; one had arthralgia and wass positive for rheumatoid factor and antinuclear an bodies; and three had systemic lupus erythematosus; two systemic sclerosis, one polymyositis, and on thyrotoxicosis and arthralgia without detectabfe autoantibodies.

\section{LUNG SPECIMENS}

Lung specimens were obtained by open biopsy in cases, by drill biopsy in one, and from necropsixs performed within one day of death in six casere. Specimens from different portions from the sanfie lung or lobe were examined in 6 cases, and in one patient a lung biopsy and a necropsy specimen taken 17 months apart were available for comparisoff. Most biopsy specimens were obtained from compaf 1 able sites in the lateral aspect of the right lung in the region of the oblique fissure. Only one of fow $r$ biopsy specimens from the left lung was from the lingula, as the changes in this area are frequent $\vec{y}$ unrepresentatively severe. ${ }^{716}$ Specimens were snapsfrozen fresh on carbon dioxide ice and stored at $-70^{\circ} \mathrm{C}$ until examination.

Table 1 Clinical features of the 25 patients with cryptogenic fibrosing alveolitis

\begin{tabular}{|c|c|c|c|c|c|c|c|c|}
\hline $\begin{array}{l}\text { Patient } \\
\text { No }\end{array}$ & Sex & $\begin{array}{l}\text { Age at biopsy } \\
(y)\end{array}$ & Smoking & $\begin{array}{l}\text { Duration of } \\
\text { symptoms }(m)\end{array}$ & $\begin{array}{l}\text { FVC } \\
\text { (\% predicted) }\end{array}$ & $\begin{array}{l}\text { KCO } \\
\text { (\% predicted) }\end{array}$ & $\begin{array}{l}\text { Lavage (days } \\
\text { before (+) } \\
\text { or after (-) } \\
\text { biopsy) }\end{array}$ & $\begin{array}{l}\text { Lavage fuid } \overline{\mathrm{O}} \\
\text { lymphocytes }\end{array}$ \\
\hline
\end{tabular}

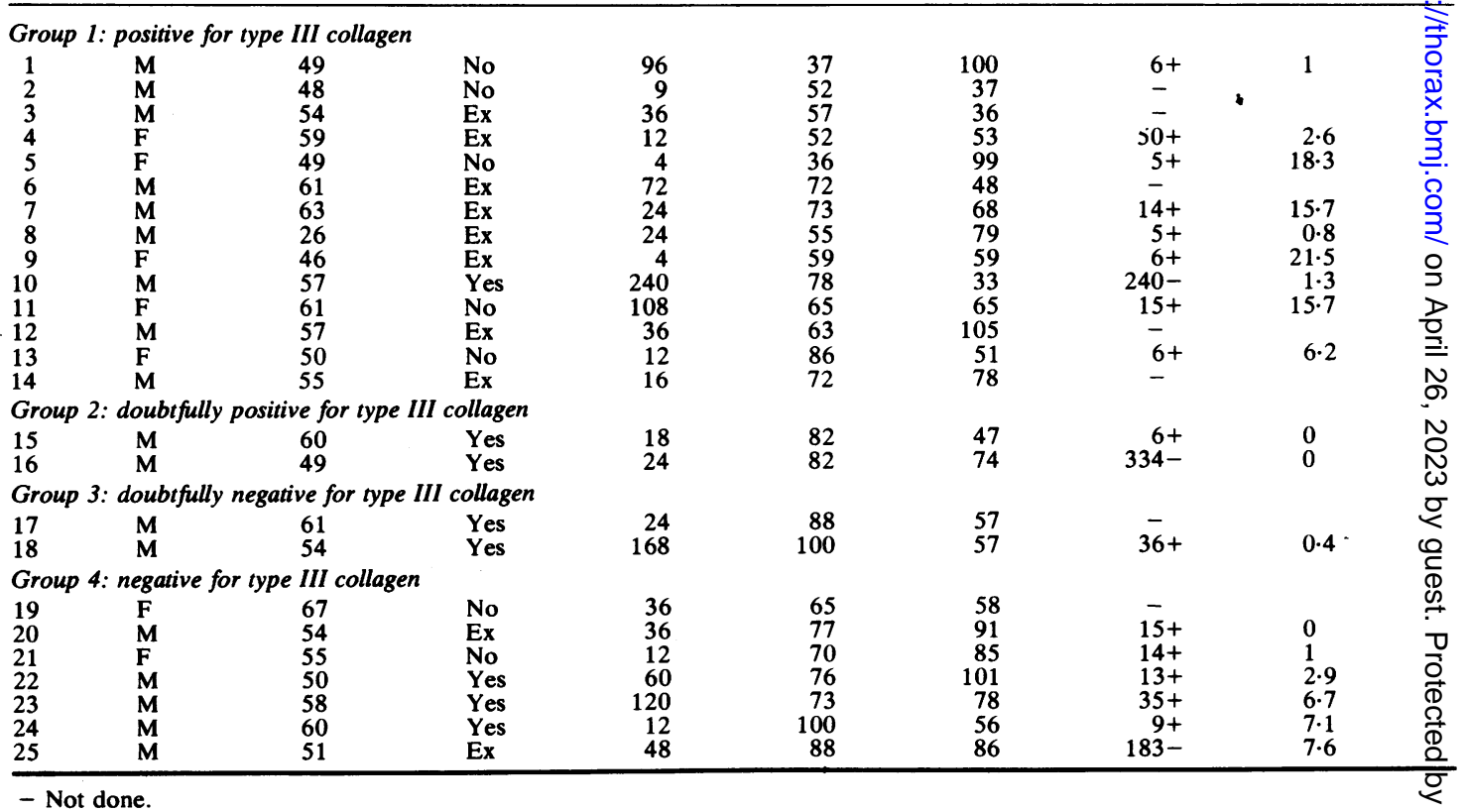


TYPE-SPECIFIC COLLAGEN

\section{IMMUNOFLUORESCENCE}

Antibodies to native triple helical bovine collagen types I, II, and III were raised in guinea-pigs and isolated, and their specificity was verified. ${ }^{17} 18$ Highly purified antibodies to bovine type IV collagen raised in rabbits were obtained from Professor AJ Bailey (Agricultural Research Council, Langford, Bristol). These four type-specific collagen antibodies were used in an indirect-immunofluorescence technique. ${ }^{13}$ Optimal dilutions of reactants determined on different human adult and fetal tissues were used on all lung specimens. Eight serial $4-\mu \mathrm{m}$ sections from each specimen were cut on a Bright's cryostat. Four were fixed in formaldehyde and stained with haematoxylin and eosin ( $\mathrm{H}$ and $\mathrm{E}$ ), modified Glees' silver impregnation, Miller's elastin van Gieson, and Masson's trichrome stains respectively. ${ }^{13}$ The remaining four sections were treated with one of the four collagen antibodies in the indirect immunofluorescence technique.

\section{HISTOLOGICAL ASSESSMENT}

Microscopy of the immunofluorescence sections was performed under transmitted ultraviolet light. ${ }^{13}$ This combination provided contrast between the specific apple-green fluorescence of collagen binding the fluorescent conjugate and the non-specific blue "autofluorescence" caused by the refractile property of the tissues. The latter permitted histological orientation even in fibrotic lung with confusing distortion of architecture.

The following features were assessed: (1) Presence of collagen types in corresponding sites. (2) Presence of type-III-collagen fuorescence in alveolar walls (normally barely detectable by this method, with the batch of reactants used ${ }^{13}$ ): negative - none detected; doubtful negative - faint apple-green fluorescence of fibres, but of doubtful significance; doubtful positive - $<25 \%$ of tissue section abnormal, but with increased type III collagen; positive increased type III collagen in greater part of section.

The $\mathrm{H}$ and $\mathrm{E}$ section and connective-tissuestained specimens were examined by light microscopy and a four-point score was used to assess alveolar wall fibrosis, alveolar wall thickening, architectural destruction, intra-alveolar cellularity, and cellular infiltrate. In addition, each specimen was graded as "cellular" — abnormal increase in intra-alveolar and interstitial mononuclear cells, with little fibroblast or connective tissue deposition; "fibrotic" - connective tissue accumulation with variable numbers of interstitial fibroblasts but few inflammatory cells; or "mixed" - roughly equal proportions of the above features.

Owing to the subjective nature of these examina- tions the following procedures were adopted: (1) All immunofluorescence and light microscopy was done by one observer without knowledge of the patients' clinical details. (2) Indirect immunofluorescence studies were performed on biopsy specimens in six batches, with previously determined optimal dilutions of the single set of reàctants being used on each. The appropriate controls ${ }^{19}$ for indirect immunofluorescence and a "control tissue" (human fetal lung at 20 weeks' gestation) were included with each batch of lung samples. Six pathological specimens were processed on two different occasions. The same interpretation of fluorescence was made on each, confirming minimal interbatch variation. (3) The indirect immunofluorescence and light microscopy studies were performed on separate occasions and repeated several days later.

\section{CLINICAL COURSE AND RESPONSE TO \\ TREATMENT}

The patients' clinical course was considered in two parts: a period of six months before lung biopsies studied retrospectively, and (in all except those from whom necropsy specimens were obtained) a period of at least six months assessed prospectively after biopsy. All assessments were based on a four-point clinical grading of dyspnoea; measurement of forced vital capacity (FVC); measurement of transfer factor for carbon monoxide (TLCO) by the singlebreath method and estimation of carbon monoxide transfer corrected for volume of ventilated lung (KCO) on the basis of lung volume determined by a helium dilution method; and chest radiographs read by two observers independently using the ILO/ UICC scoring system. ${ }^{20}$ Plates were read individually in random order and then in pairs to assess change. FVC and KCO were expressed as percentages of values predicted for sex, age, and height ${ }^{21}$ and only changes of greater than $10 \%$ were considered to indicate improvement or deterioration. The clinical assessment was repeated on two or more occasions during the six-month follow-up period. "Clinical change" was defined as change in two of these four parameters, sustained for six months. Initial and follow-up assessments and treatment were supervised by clinicians who did not know the results of the indirect immunofluorescence studies.

Corticosteroid treatment comprised a daily dose of $40-50 \mathrm{mg}$ prednisone (adjusted for age, weight, and sex) given for 4 to 6 weeks. Where improvement was observed a gradual reduction over several months was attempted. When unacceptably high doses were required to maintain improvement, or when no response was observed, other treatments were attempted (table 2). During the course of this 
Table 2 Response to treatment

\begin{tabular}{ccccc}
\hline Group & $1:$ & Positive for type III collagen & \\
1 & $\downarrow$ & $\downarrow$ & 0 & 0 \\
2 & $\downarrow$ & $\mathrm{PM}$ & 0 & 0 \\
3 & $\mathrm{PM}$ & 0 & 0 \\
4 & $\uparrow$ & $\uparrow$ & + & + \\
5 & $\uparrow$ & + & + \\
6 & & $\mathrm{PM}$ & 0 & 0 \\
7 & $\uparrow$ & + & 0 \\
8 & $\uparrow$ & $\uparrow$ & + & 0 \\
9 & $\downarrow$ & $\uparrow$ & + & + \\
10 & $\downarrow$ & $\uparrow$ & 0 & 0 \\
11 & $\downarrow$ & $\uparrow$ & + & 0 \\
12 & $\downarrow$ & $\mathrm{PM}$ & + & + \\
13 & $\downarrow$ & $\uparrow$ & - & - \\
14 & $\downarrow$ & $\mathrm{PM}$ & + & 0 \\
Group & $2:$ doubtfully positive for type III collagen
\end{tabular}

$\begin{array}{lllll}15 & \rightarrow & \rightarrow & 0 & 0 \\ 16 & \rightarrow & \rightarrow & 0 & 0\end{array}$

Group 3: doubtfully negative for type III collagen $\begin{array}{lllll}17 & \rightarrow & \downarrow & 0 & 0 \\ 18 & \rightarrow & \rightarrow & - & -\end{array}$

Group 4: negative for type III collagen

$\begin{array}{lllll}19 & \rightarrow & \text { PM } & - & \\ 20 & \downarrow & \uparrow & + & 0 \\ 21 & \downarrow & \uparrow & + & + \\ 22 & \rightarrow & \rightarrow & 0 & 0 \\ 23 & \rightarrow & \rightarrow & - & - \\ 24 & \rightarrow & \rightarrow & - & - \\ 25 & \rightarrow & \rightarrow & - & \end{array}$

- Not done.

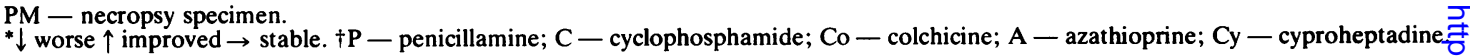

investigation several regimens were being studied; they included cyclophosphamide $(100-120 \mathrm{mg}$ daily) in combination with colchicine $(0.5 \mathrm{~g}$ three times daily) and cyproheptadine (4 $\mathrm{mg}$ three times daily), azathioprine (150 mg daily), and penicillamine (initially $125 \mathrm{mg}$ daily increasing to $1 \mathrm{~g}$ daily). "Treatment response" was defined as an improvement on treatment in two of the four parameters mentioned above, sustained for six months. Treatment was instituted within one month of the date of biopsy in 13 cases, and within two months in a further three; three were not treated. The six patients from whom necropsy specimens were obtained were treated from their date of presenta 3 tion until death.

\section{BRONCHOALVEOLAR LAVAGE}

Bronchoalveolar lavage was performed on 19 patients, mostly (12 cases) within the 15 days befores the biopsy. Four lavages were undertaken from fou

[Facing page]

Photomicrographs of type-specific collagen fuorescence in serial sections of lung from patients with cryptogenic fibrosing alveolitis, processed by an indirect immunoftuorescence technique, with transmitting ultraviolet light achieving contrast $\mathrm{W}$ between specific collagen fuorescence (apple-green), blue autoftuorescence of unstained tissues, and light blue or white of elastic fibres.

(a) and (b) Patient 24: (a) Type-I-collagen fuorescence in thickened alveolar walls. (b) Absence of type-III-collagen fuorescence in the same area. Elastic fibres are abnormally prominent and represent accumulation or condensation (or both) in an area of fibrosis. In (a) pieces of alveolar wall in right upper and left lower corners of the field have been lost in the preparation of the section. This biopsy specimen was scored as negative for type III collagen. (About $\times 260$.)

(c), (d), and (e) Patient 13: Fluorescence of type I, III, and IV collagens respectively. The intensity and profusion of type-III-collagen fuorescence is almost that of type I, and type III is present in all layers of the alveolar walls. The alveoli ar reduced in size and contain cellular exudate. This biopsy specimen was scored as positive for type III collagen. (e) Type-IV-collagen fuorescence delineating alveolar and capillary (shown with arrow) basement membranes. (About $\times 190, \$$ 

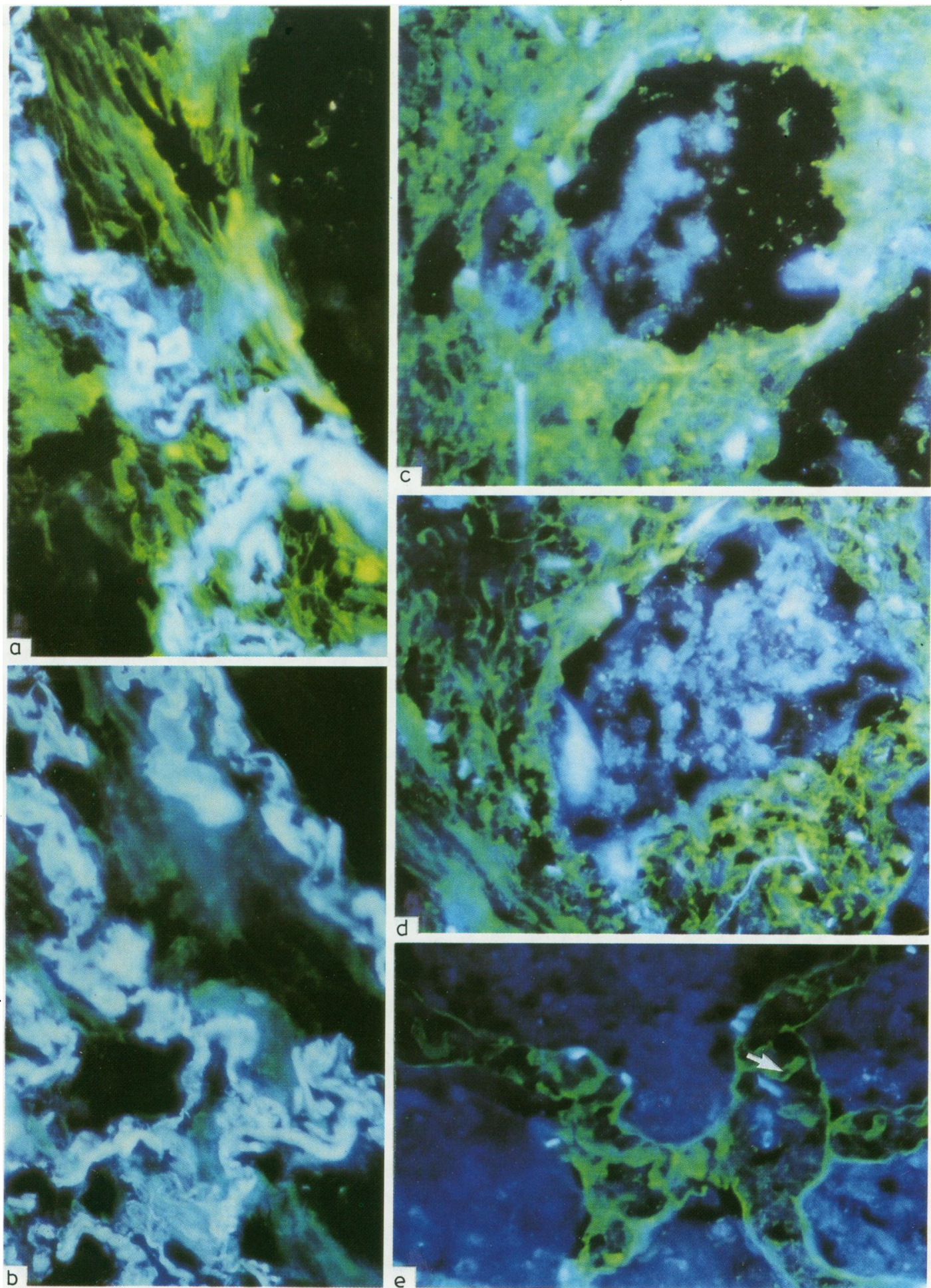

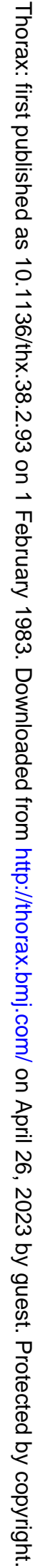


Table 3 Comparison between patients positive and negative for type III collagen

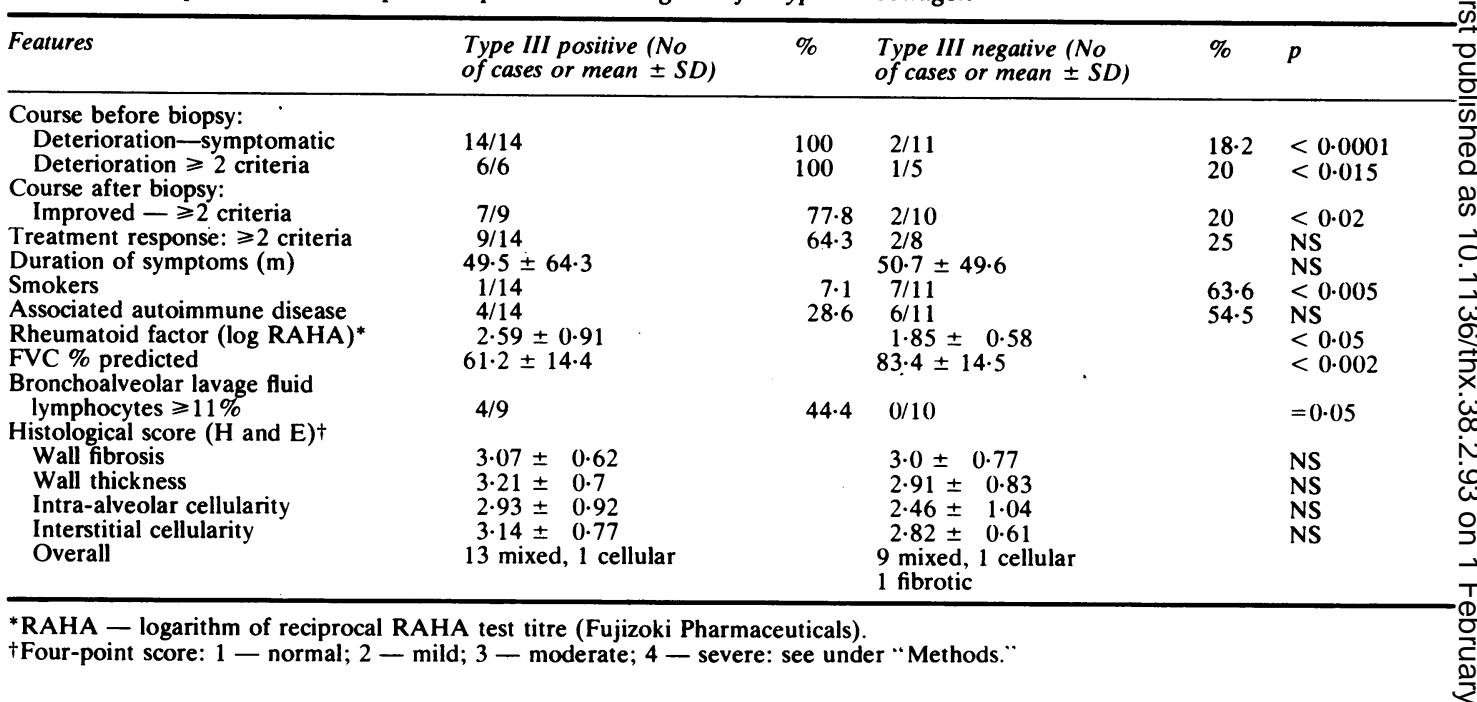

to nine weeks and one six months before biopsy. In two patients lavage was performed outside the sixmonth period ( 8 and 11 months before), but the data have been included as their clinical course did not change during the observation period or up to the time of lavage.

STATISTICAL ANALYSIS

The Mann-Whitney $U$ test or $2 \times 2$ tables with Fisher's exact test were used for group comparisons.

\section{Results}

\section{TYPE-SPECIFIC COLLAGEN} IMMUNOFLUORESCENCE

Type I collagen predominated in all sites of lung fibrosis. In areas where fibre bundles were closely packed the type-I-collagen fluorescence was weaker, type III collagen could not be seen, and a degree of blue, non-specific autofluorescence was observed in the ultraviolet light. ${ }^{13}$ In specimens from 14 patients, however, type III collagen could be easily identified, and was usually found in subepithelial sites or in loosely arranged fibrils between densely packed type I fibres in alveolar walls (fig). In several biopsy specimens it had a fluorescent intensity and widespread distribution like that of type I. Type III collagen was also found in its normal location in bronchial submucosa and subintima of vessels. ${ }^{13}{ }^{14}$ Comparisons with $\mathrm{H}$ and $\mathrm{E}$ sections confirmed that the abnormal collections of type III collagen were in areas of cellularity (chronic inflammatory cells and fibroblasts), whereas relatively acellular areas of dense fibrous tissue contained only type $I$.

The grouping of patients on the basis of demon- strable type III collagen is shown in tables 1 and $2 \cdot \vec{\bullet}$ In 14 cases the features of activity were patchy, even within a single lung specimen. The unavoidable problem of lung sampling was illustrated in three of the six cases in which two biopsy specimens taken from different parts of the lung were examined. In two cases (5 and 11) one specimen was scored as $\frac{2}{D}$ "doubtful positive," whereas the second was $\varrho$ definitely positive. In case 23 one sample was "nega- $\overrightarrow{\bar{O}}$ tive" and the other "doubtful negative." In the remaining three cases, however, both specimens received the same score. The patients in the "doubtful positive", "doubtful negative" and "negative" categories were grouped together in the analysis. $\frac{\text { o }}{N}$ When the "doubtful" groups were omitted the associations with clinical features were similar.

HISTOLOGICAL ASSESSMENT OF FIBROSIS AND CELLULARITY

The biopsy specimens from all patients had featureso fulfilling the criteria for "usual interstitial pneumonia" 4 but in different stages of fibrosis: two cases (4 and 21$)$ were predominantly cellular, one $\frac{\mathrm{N}}{\mathrm{N}}$ was fibrotic (case 19) and the remainder weres mixed. Comparison of collagen immunofluorescence $N$ (type I or III or both) and connective tissue stains N confirmed that in areas of fibrosis with minimal type III collagen all stains compared favourably with fluorescence. In locations where type III collagen was more plentiful, however, the silver吕 impregnation method correlated most accurately with type III collagen immunofluorescence.

CLINICAL COURSE AND RESPONSE TO

TREATMENT

Steady deterioration in the six months before biopsy 
was observed in 16 patients (table 2).

Nine of the 18 patients treated with corticosteroids (and one treated with a combination of corticosteroids and cyclophosphamide) during the six months showed a treatment response. Four of these, who were put on alternative treatment because of corticosteroid side effects, continued to improve.

Seven of the nine non-responders to corticosteroids were treated with alternative regimens but none improved. Three patients were not treated with corticosteroids but received either a combination of cyclophosphamide, colchicine, and cyproheptadine (one of two improved) or pencillamine and immunosuppressants (no response).

The terminal events in the six cases in which necropsy specimens were obtained were: ischaemic heart disease (case 19), pulmonary thromboembolism (case 2), Haemophilus septicaemia (case 14), fulminant influenza due to influenza B virus (case 3 ), herpes simplex (case 12), and measles pneumonia (case 6).

\section{COMPARISON OF PATIENTS POSITIVE AND}

NEGATIVE FOR TYPE III COLLAGEN

All the patients who were positive for type III collagen (table 2) were deteriorating before biopsy, and continued to show signs of disease activity after biopsy or the start of treatment; there was continued deterioration in five and response to treatment in nine. In contrast, most patients who were negative for type III had a stable course before biopsy, only two showing features of deterioration. Most but not all the treatment responders were positive for type III, the trend not reaching statistical significance (table 3 ). Thus a strong positive association was observed between disease activity and the presence of type III collagen in lung biopsy specimens, but not between the latter and treatment response. This association was not accounted for by differences in histological score and there were no significant differences between the groups when analysed for age, sex, presence of crepitations, or the number of

Table 4 Comparison of treatment responders and non-responders

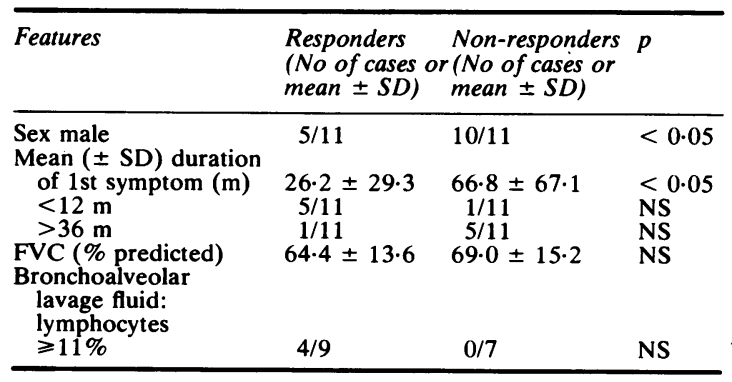

postmortem specimens in each. The type-IIIpositive group contained fewer smokers $(p<$ 0.005 ), but many were ex-smokers (eight out of 14). Cessation of smoking was possibly prompted by their deteriorating clinical course and poorer ventilatory function. The forced vital capacities were significantly lower than in the type-III-negative group.

All patients with an increased proportion of lymphocytes in bronchoalveolar lavage fluid $(11 \%$ or higher) were type III positive. No difference in total cell yield, cell yield per millilitre of lavage fluid, or proportion of neutrophils or eosinophils was found.

\section{COMPARISON OF TREATMENT RESPONDERS AND} NON-RESPONDERS

Treatment responders (table 4) had had symptoms for a shorter time before treatment $(p<0.05)$. No significant group differences existed in clinical signs, lung function tests, symptoms of associated autoimmune disease, or proportions of cells in bronchoalveolar lavage fluid. All four patients with an increased percentage of lymphocytes in the lavage fluid were, however, in the responder group ( $\mathrm{p}=$ 0.07 ), a trend that might have been significant had larger numbers of patients been studied. The light microscopy histological scores given for responders and non-responders were not significantly different.

\section{Discussion}

For the type-specific collagen immunofluorescence method highly purified type-specific antibodies are required. Cross-reactions between type I and type III antibodies are difficult if not impossible to eliminate, but a small degree of cross-reaction is acceptable since the object is to confirm only semiquantitatively the presence or absence of type III collagen. Variations in specificity and avidity of different batches of antibody are usual, and each batch requires standardisation by comparison with previous batches on control substrates. ${ }^{22} 23$ As with histochemical stains, quantification is based on the area occupied by the positively stained tissue and its colour intensity, which cannot be measured accurately. An added difficulty with collagen immunofluorescence is its dependence on the coating of collagen fibres with fluorescent antibody complexes, a process favouring loose reticular fibres, which are accessible to the reactants, rather than tightly packed fibre bundles. Since type I has the latter form it is underestimated by comparison with type III.

Other potential weaknesses of this method are the subjective nature of the observations; the patchy distripution of the pathological process in cryptogenic fibrosing alveolitis, resulting in poor correla- 
tion between biopsy specimens from different lung segments; the infrequency with which biopsy specimens of adequate size are obtained; and the possibility that infections such as pneumonia, which occurred terminally in a few cases in this study, might alter the collagen ratios. Useful precautions to ensure accuracy and reproducibility have been mentioned in the paper and elsewhere. ${ }^{13}$

There are few published studies of the changes in collagen types in cryptogenic fibrosing alveolitis. ${ }^{24} 25$ Seyer $e^{t} a^{24}$ performed biochemical assays of collagen types in postmortem lung specimens from five patients with idiopathic pulmonary fibrosis and showed that only $12-24 \%$ of collagen in diseased lungs was of type III, compared with $31 \%$ in normal lungs. Although apparently at variance with the results of the current study, these data might provide complementary information. In contrast to the immunofluorescence technique, biochemical extraction provides a quantitative measure of collagen content and of the ratio of collagen types in the total collagen solubilised. ${ }^{26}$ The different solubility of the collagen types, however, introduces a potential source of error, types III and IV being more resistant to extraction than type $\mathrm{I}^{27}$ Because the immunofluorescence technique is highly sensitive and shows deposits of collagen which are outside the range of biochemical detection, a close correlation between biochemical and immunofluorescence findings need not be expected.

Other differences between the current study and that of Seyer $e t a^{24}$ is that the latter was performed on lungs from patients who had died with cryptogenic fibrosing alveolitis, and no attempt was made to correlate biochemical findings with histopathological or clinical features. ${ }^{24}$ Necropsy specimens of lung from patients with cryptogenic fibrosing alveolitis are known to contain more fibrosis and less inflammatory cellularity than biopsy specimens, ${ }^{2}$ a trend also observed in the current study, and it is possible that Seyer et al studied lungs containing mature inactive fibrosis with predominantly type I collagen, which by the indirect immunofluorescence method would have been classed as "type III negative." A temporal transition of collagen fluorescence was observed in patient 7 . The initial biopsy specimen was type III positive; he was treated and showed improvement, but died 17 months later from adenocarcinoma of the lung. The necropsy specimen was type III negative. Specimens showing "type-III-positive" immunofluorescence may not have a greater-than-normal proportion of type III collagen since, provided that the total collagen content (both type I and type III) rises, type III will become histologically evident without an alteration in proportions.
Although clinically active, the process was not uniformly early in the patients classed as type II positive. Physiological measurements of lung func을 tion gave worse results than in those negative fo름 type III collagen and the grading of fibrosis on lighs microscopy was severe. The association of type II $\mathbb{E}$ collagen with clinical activity was therefore non accounted for by an association with any of the usua details obtained from the history or even routine histological examination or by aspects of pulmonary physiology.

Furthermore, most patients who responded toक्रे treatment came from the type-III-positive group The difference between responders and non $\infty$ responders requires separate consideration. Theo former had had a shorter duration of symptoms ${ }^{3}$ an $\delta_{0}^{5}$ the group included all those with an increased per centage of lymphocytes in bronchoalveolar lavage fluid. ${ }^{7}$ These observations are consistent with thos of Rudd et al, ${ }^{28}$ who showed that responders had has a shorter duration of disease and worse FVC\% a initial assessment than non-responders.

As in other series ${ }^{4-612}$ the responder group alsळo showed a trend towards more cellularity and less alveolar fibrosis and architectural destruction. Eack of these associations has a varying but small value ire predicting response to treatment. Together and it individual cases their predictive value increases. The presence or absence of type III collagen according t\& the immunofluorescence method is another usefut parameter to add to this combined assessment.

Other clinically relevant observations were mader in this study. No patient in the "type-III-positive? group had a quiescent or stable course, and none improved spontaneously. Those not responding to steroid treatment had a progressively downhi立 course. It is therefore recommended that "typeo III-positive" patients who fail to respond to treat ment should receive alternative forms of treatmerif in an attempt to arrest the process. On the othe hand, most patients with no type-III-collageg fluorescence had a stable course during the observas tion period and were not affected by treatment, suge gesting that they did not require treatment. Absence of type III collagen in biopsy specimens might there fore strengthen the decision to withhold potentially harmful treatment, at least until there is clinical evi dence of disease activity.

Finally, because type III collagen is associateg with active fibrogenesis, patients in this categor might be more responsive to the effects of therapeuf tic agents such as penicillamine, ${ }^{2930}$ prolin analogues, and colchicine, which act only during coB lagen synthesis or fibril formation (or both), and ar ineffective in the presence of mature, dense scar tist sue. Possibly by careful selection of patients for 
treatment with these agents the evaluation of their therapeutic efficacy will improve and indications for their use emerge.

We are grateful to ICI South Africa (Pharmaceuticals) Ltd, Lilly Industries Ltd, and Dista Pharmaceuticals (England) for financial support and to Mr P Townshend for technical help.

\section{References}

${ }^{1}$ Turner-Warwick M, Haslam P. Antibodies in some chronic fibrosing lung diseases. 1- Non-organ-specific autoantibodies. Clin Allergy 1971;1:83-95.

${ }^{2}$ Turner-Warwick M, Burrows B, Johnson A. Cryptogenic fibrosing alveolitis. 1 - Clinical features and their influence on survival. Thorax 1980;35:171-80.

${ }^{3}$ Turner-Warwick M, Burrows B, Johnson A. Cryptogenic fibrosing alveolitis. Response to corticosteroid treatment and its effect on survival. Thorax 1980;35:593-9.

${ }^{4}$ Carrington CB, Gaensler EA, Coutu RE, Fitzgerald MX, Gupton RG. Natural history and treated course of usual desquamative interstitial pneumonia. $N$ Engl J Med 1978;298:801-9.

5 Stack BHR, Choo-Kang YFJ, Heard BE. The prognosis of cryptogenic fibrosing alveolitis. Thorax 1972;27:535-42.

- Wright PH, Heard BE, Steel SJ, Turner-Warwick M. Cryptogenic fibrosing alveolitis: assessment by graded trephine lung biopsy histology compared with clinical, radiographic and physiological features. $\mathrm{Br} J$ Dis Chest 1981;75:61-70.

7 Haslam PL, Turton CWG, Heard B, et al. Bronchoalveolar lavage in pulmonary fibrosis: comparison of cells obtained with lung biopsy and clinical features. Thorax 1980;35:9-18.

${ }^{8}$ Crystal RG, Fulmer JD, Roberts WC, Moss ML, Line BR, Reynolds HY. Idiopathic pulmonary fibrosis. Clinical, histologic, radiographic, physiologic, scintigraphic, cytologic and biochemical aspects. Ann Intern Med 1976;85:769-88.

9 Weinberger SE, Kelman JA, Elson NA, et al. Bronchoalveolar lavage in interstitial lung disease. Ann Intern Med 1978;89:459-66.

${ }^{10}$ Reynolds HY, Fulmer JD, Kazmierowski JA, Roberts WC, Frank MM, Crystal RG. Analysis of cellular and protein content of bronchoalveolar lavage fluid from patients with idiopathic pulmonary fibrosis and chronic hypersensitivity pneumonitis. J Clin Invest 1977;59: 165-75.

${ }^{11}$ Hunninghake GW, Fulmer JD, Young RC, Gadek JE, Crystal RG. Localization of the immune response in sarcoidosis. Am Rev Respir Dis 1979;120:49-57.

12 Scadding JG, Hinson KFW. Diffuse fibrosing alveolitis (diffuse interstitial fibrosis of the lungs). Thorax 1967;22:291-304.

${ }^{13}$ Bateman ED, Turner-Warwick M, Adelmann BC. Immunohistochemical study of collagen types in human foetal lung and fibrotic lung disease. Thorax 1981;36:645-53.
${ }^{14}$ Gay S, Balleisen L, Remberger K, Fietzek PP, Adelmann BC, Kühn K. Immunohistochemical evidence for the presence of collagen type III in human arterial walls, arterial thrombi, and in leucocytes incubated with collagen in vitro. Klin Wochenschr 1975;53: 899-902.

15 Wick G, Brunner H, Penner E, Timpl R. The diagnostic application of specific antiprocollagen sera. II Analysis of liver biopsies. Intern Arch Allergy Appl Immunol 1978;56:316-24.

${ }^{16}$ Gaensler EA, Carrington CB. Open biopsy for chronic diffuse infiltrative lung disease: clinical, roentgenographic and physiological correlations in 502 patients. Ann Thorac Surg 1980;30:411-26.

${ }^{7}$ Adelmann BC, Gentner GJ. Dependence of the antibody response of guinea-pigs to collagen on the type of adjuvant and on the conformation of the antigen. $Z$ Immunitaetsforsch Immunobiol 1977;152:369-80.

18 Adelmann BC, Gentner GJ, Hopper K. A sensitive radioimmunoassay for collagen. J Immunol Methods 1973;3:319-36.

19 Johnson GD, Holborow EJ, Dorling J. Immunofluorescence and immunoenzyme techniques. In: Weir DM, ed. Handbook of experimental immunology. 3rd ed. Oxford: Blackwell, 1978: 15.1-30.

${ }^{20}$ International Union Against Cancer Committee. Cincinnati classification of the radiographic appearances of pneumoconioses: a co-operative study by the UICC Committee. Chest 1970;58:57-67.

${ }^{21}$ Cotes JE. Lung function: assessment and application in medicine. 3rd ed. Oxford: Blackwell, 1975.

${ }^{22}$ Nowack H, Gay S, Wick G, Becker U, Timpl R. Preparation and use in immunohistology of antibodies specific for type I and type III collagen and procollagen. J Immunol Methods 1976;12:117-24.

${ }^{23}$ Becker U, Nowack H, Gay S, Timpl R. Antibodies against the aminoterminal region in bovine type III collagen. Immunology 1976;31:57-65.

${ }^{24}$ Seyer JM, Hutcheson ET, Kang AH. Collagen polymorphism in idiopathic chronic pulmonary fibrosis. J Clin Invest 1976;57:1498-1507.

${ }^{25}$ Fulmer JD, Bienkowski RS, Cowan MJ, et al. Collagen concentration and rates of synthesis in idiopathic pulmonary fibrosis. Am Rev Respir Dis 1980;122:289 301.

${ }^{26}$ Hance AJ, Crystal RG. The connective tissue of lung. Am Rev Respir Dis 1975;112:657-711.

${ }^{27}$ Epstein ED. $\left[\alpha_{1} \text { (III) }\right]_{3}$ Human skin collagen: release by pepsin digestion and preponderance in foetal life. $J$ Biol Chem 1974;249:3225-32.

${ }^{28}$ Rudd RM, Haslam PL, Turner-Warwick M. Cryptogenic fibrosing alveolitis: relationships of pulmonary physiology and bronchoalveolar lavage to response to treatment and prognosis. Am Rev Respir Dis 1981;124:1-8.

${ }^{29}$ Herbert CM, Lindberg KA, Jayson MIV, Bailey AJ. Biosynthesis and maturation of skin collagen in scleroderma, and effect of D-penicillamine. Lancet 1974;i:187-92.

${ }^{30}$ Lorber A. Penicillamine therapy for rheumatoid lung disease: effects of protein sulfhydryl groups. Nature 1966;210:1235-6. 